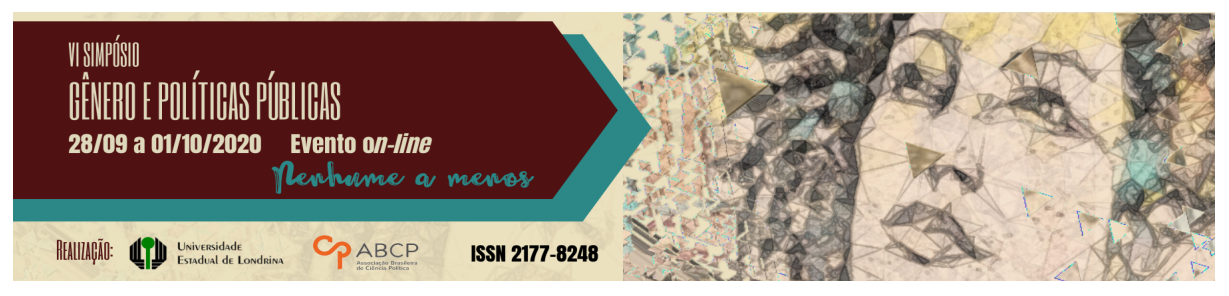

\title{
Lélia Gonzalez e a articulação de gênero, raça e classe
}

\author{
Renata Gonçalves ${ }^{1}$
}

\section{Resumo}

Nesta comunicação, apresentarei uma das maiores intelectuais que o Brasil já teve Lélia Gonzalez, mulher, feminista, negra. Em 2018, a União dos Coletivos Pan-Africanistas (UCPA), reuniu cuidadosamente a maioria dos textos da autora no livro Lélia Gonzalez: primavera para as rosas negras e, finalmente, o grande público brasileiro, em especial feministas e ativistas do movimento negro, começa a ter contato com a autora, que recupera termos "embolados" da psicanálise freudiana e lacaniana, do diálogo com Althusser, das críticas ao pensamento social (racista) brasileiro e dos embates com o movimento feminista, com reivindicações que escamoteiam a dominação e a exploração presentes na relação entre mulheres brancas e negras no Brasil.

Palavras-chave: Lélia Gonzalez; feminismo negro; racismo; sexismo.

\section{Lélia Gonzalez and the articulation of gender, race and class}

\section{Abstract}

In this communication, I will present one of the greatest intellectuals that Brazil has ever had Lélia Gonzalez, woman, feminist, black. In 2018, the Union of Pan-Africanist Collectives (UCPA), carefully gathered most of the author's texts in the book Lélia Gonzalez: spring for black roses and, finally, the great Brazilian public, especially feminists and activists of the black movement, begins to have contact with the author, who recovers "embolized" terms from Freudian and Lacanian psychoanalysis, from dialogue with Althusser, from criticisms of Brazilian (racist) social thought and from clashes

1 Doutora em Ciências Sociais pela Unicamp. Docente da Universidade Federal de São Paulo, campus Baixada Santista; coordenadora, na mesma instituição, do Núcleo de Estudos Heleieth Saffioti - NEHS.

GT 01 - Amefricanizando o feminismo: mulheres negras saindo da invisibilidade 
with the feminist movement, with claims that conceal domination and exploitation present in the relationship between white and black women in Brazil.

Keywords: Lélia Gonzalez; black feminism; racism; sexism.

\section{Introdução}

A trajetória intelectual e política de Lélia Gonzalez nos permite conhecer um pouco mais da própria condição das mulheres intelectuais negras no Brasil, pois é impossível separar a vida pessoal da militância acadêmica e política da intelectual negra. Lélia, assim como a maior parte das mulheres negras brasileiras, passou por um processo violento de busca pela brancura, negando a si mesma. Somente após um episódio traumático em sua vida amorosa, a antropóloga se voltou para sua ancestralidade africana. Em referência oposta à violência do racismo no processo de construção do ser negro, como apontado no livro Tornar-se negro, de Neusa Santos Souza (1983), Lélia fez o caminho de volta às origens até definitivamente enegrecer.

Quem foi Lélia Gonzalez? Questão que, infelizmente, precisa ser feita com frequência, pois como observou Sueli Carneiro, embora o movimento negro tenha produzido grandes intelectuais, a academia convencional nunca reconheceu suas contribuições ao pensamento social brasileiro. Lélia, apesar de sua farta produção teórica, permanecia uma desconhecida no ambiente letrado da intelligensia brasileira.

No coração de suas inquietações teóricas e práticas, está o racismo que, ao lado do sexismo, é considerado uma verdadeira neurose da cultura brasileira. Ao questionar os alicerces do pensamento social brasileiro, principalmente o mito da democracia racial, Lélia nos presenteia com formulações teóricas como o "pretuguês" e o "amefricanismo" etc., que fazem dela a pioneira de um pensamento interseccional no Brasil, demonstrando que a articulação de gênero, de raça e de classe produz efeitos violentos, em particular, sobre as mulheres negras. 


\section{Conhecendo Lélia Gonzalez}

Lélia de Almeida nasceu em 1935, na cidade de Belo Horizonte, Minas Gerais. Foi a décima-sétima de dezoito filhos de uma empregada doméstica de ascendência indígena e de um ferroviário negro. Em 1942, migrou com sua família de Belo Horizonte para a cidade do Rio de Janeiro, quando ainda era criança aos 07 anos de idade, com o propósito de se juntarem ao irmão mais velho, que se tornara jogador de futebol no Flamengo Futebol Clube.

Lélia, na chegada à cidade maravilhosa, trabalhou como babá dos filhos de diretores do Flamengo, clube em que o irmão Jaime era jogador. Na família da pequena mineira, todos trabalhavam, os estudos se reduziam aos primeiros anos da escola primária. González, a este respeito, no depoimento que deu aos organizadores do livro Patrulhas ideológicas, salientou que "o esquema ideológico internalizado pela família era esse: estudava-se até a escola primária e, depois, todo mundo ia à batalha [...] pra ajudar a sustentar o resto da família" (PEREIRA; HOLLANDA, 1980, p. 202). Ela, porém, ao contrário de seus irmãos e irmãs, logo teve a possibilidade de estudar em um dos melhores colégios cariocas (RATTS; RIOS, 2010).

O racismo esteve presente na vida de Lélia Gonzalez. No entanto, suas reflexões sobre discriminação e preconceito só ocorrem na fase adulta. Lélia compreendeu o quanto o discurso pedagógico brasileiro foi responsável por uma lavagem cerebral. Para a autora, à medida que aprofundava seus conhecimentos, mais rejeitava sua condição de mulher negra. Na faculdade, como ressalta, ela "já era uma pessoa de cuca, já perfeitamente embranquecida" (GONZALEZ, 2018, p. 82). Tornou-se a "pretinha legal, muito inteligente, [que] os professores gostavam". Para ser aceita, "usava peruca, esticava o cabelo, gostava de andar como uma lady" (GONZALEZ, 2018, p. 82).

Lélia González foi umas das poucas mulheres negras de sua geração que teve acesso ao ensino superior. Graduou-se em História e Geografia, depois fez pós-graduação em Comunicação e Antropologia 
e, por fim, fez cursos livres de Sociologia e Psicanálise (RATTS; RIOS, 2010).

Para Lélia, a experiência do racismo que a empurra para a militância foi muito dolorosa. Todo o esforço que fez para adotar a estética da brancura não a protegeu da dor do racismo. Começou um relacionamento com um homem branco, mas o casamento inter-racial foi rejeitado pela família de ascendência europeia do marido, Luiz Carlos Gonzalez (de quem ela mantém o sobrenome), que terminou por suicidar-se. Esta tragédia pessoal marcou para sempre a vida de Lélia Gonzalez, que agora faria o caminho inverso para tornar-se negra. Enegrecer significou uma profunda mudança pessoal, teórica e política.

A partir daí, fui transar o meu povo mesmo, ou seja, fui transar candomblé, macumba, essas coisas que eu achava que eram primitivas. Manifestações culturais que eu, afinal de contas, com uma formação em Filosofia, transando uma forma cultural ocidental tão sofisticada, claro que não podia olhar como coisas importantes. Mas, enfim, voltei às origens, busquei as minhas raízes (GONZALEZ, 2018, p. 83).

O envolvimento com organizações políticas se consolidou naquele momento, final dos anos de 1960. De acordo com Barreto (2005), Lélia passou a ser observada pelo Departamento de Ordem e Política Social (Dops) e informações sobre ela aparecem pela primeira vez nos fichários do órgão em 1972, quando foi solicitada a averiguação sobre seu possível envolvimento no "recrutamento de adeptos à doutrina marxista", na Universidade Gama Filho, onde Lélia lecionava Filosofia. A ebulição por que passa a autora a leva a muitas inserções políticas: "militou no movimento negro, fundou e atuou no Instituto de Pesquisas das Culturas Negras (IPCN), no Movimento Negro Unificado (MNU), no Coletivo de Mulheres Negras N`Zinga. Integrou a primeira composição do Conselho Nacional dos Direitos da Mulher (CNDM), entre 1985 e 1989" (Barreto, 2018a, p. 15). Além 
disso, foi integrante do Partido dos Trabalhadores e depois se filiou ao Partido Democrático Trabalhista, sendo candidata pelo primeiro a deputada estadual em 1982, e pelo segundo, candidatou-se, em 1986, à deputada federal (RATTS; RIOS, 2010).

Lélia Gonzalez foi uma intelectual muito ativa no movimento negro. Deu palestras, organizou seminários, cursos conferências, viajou em função da militância, encontrou outros personagens do Brasil e do exterior. Conheceu o racismo em outros países também e, como aqui, vivenciou as experiências de luta contra a dominação e a opressão. Neste denso percurso, desenvolveu suas teorias mais genuínas, como a neurose da cultura brasileira, a divisão racial do trabalho, lugar de negro, pretuguês e a categoria político-cultual de amefricanidade. Dos processos intelectuais aparentemente solitários, suas concepções nos fornecem elementos para compreendermos a estreita relação entre desenvolvimento do capitalismo, racismo e dominação patriarcal no Brasil.

\section{Feminismo negro e a divisão racial do trabalho}

Lélia Gonzalez foi protagonista de um dos debates mais importantes com o movimento. Dentro do movimento negro que ressurgia no final dos anos de 1970, as mulheres negras se chocaram com o machismo dos companheiros, que impunham a elas um papel secundarizado, tarefeiro etc. e as mantinham longe das instâncias decisórias. Para o homem negro, em uma sociedade atravessada pelo racismo, dominar esse espaço significava ter um dos poucos momentos para o seu protagonismo, tornando utópica a tentativa de uma divisão igualitária com as mulheres negras. Elas tinham ainda de lidar com o assédio sexual, com a sexualização/objetificação de seus corpos, o que as colocavam como "sombra" de seus companheiros. Com relação ao movimento feminista, as mulheres negras, mesmo atuantes, também não viram suas pautas serem priorizadas, em especial no que tange à ruptura com certo "modelo" feminino ao 
qual não se identificavam. A visão eurocêntrica e universalizante de mulher incapacitou o feminismo de "reconhecer as diferenças e desigualdades presentes no universo feminino, a despeito da identidade biológica" (CARNEIRO, 2003, p. 118). Outras formas de opressão, não foram percebidas, outras mulheres tiveram suas vozes silenciadas e seus corpos estigmatizados. A pauta feminista de combate ao sexismo deixou invisíveis as especificidades das mulheres negras, ignorou as tensões sociais causadas por diferenças de etnia e classe social, como se todas as mulheres fossem iguais (LEMOS, 2006).

Uma das principais críticas ao universalismo do feminismo veio de bell hooks, feminista negra estadunidense. Em seu artigo mulheres negras: moldando a teoria feminista, a autora observa que a opressão não atinge da mesma forma a todas as mulheres. A realidade social é muito mais complexa e não se reduz às experiências das mulheres brancas da classe média ocidental. Assim, afirma,

Nos Estados Unidos, o feminismo não surgiu das mulheres que são mais vitimizadas pela opressão machista, das mulheres agredidas todos os dias, mental, física e espiritualmente - as que são impotentes para mudar sua condição na vida. Estas são a maioria silenciosa. Uma marca de sua condição de vítimas é o fato de aceitarem sua sina na vida sem questionamento visível, sem protesto organizado, sem fúria ou raiva coletivas. The feminine mystique, de Betty Friedan, publicado em 1963, ainda é saudado como o livro que abriu caminho para o movimento feminista contemporâneo - a obra foi escrita como se essas mulheres não existissem. Embora o livro já tenha sido criticado e até mesmo atacado por vários motivos, volto a chamar a atenção porque certas premissas tendenciosas sobre a natureza da condição social das mulheres, postuladas inicialmente nele, continuam a moldar o teor e a direção do movimento feminista (hooks, 2015, p. 193).

De acordo com a autora, um preceito central do pensamento 
feminista moderno tem sido a afirmação de que "todas as mulheres são oprimidas". Para ela, essa afirmação sugere que todas as mulheres compartilham a mesma sina. Ora, os fatores como classe, raça, orientação sexual etc. criam uma diversidade de experiências que não podem ser apreendidas somente pela denúncia do sexismo. Angela Davis (2016) observa que nos estudos feministas clássicos as mulheres negras foram invisibilizadas, tiveram suas experiências completamente ignoradas em nome de uma homogeneização da definição de mulher, apagando, portanto, as dimensões de classe e raça/etnia.

No Brasil também encontramos expressões desta crítica ao feminismo "universal", quando despontam organizações especificamente de mulheres negras. Estas surgem com um duplo papel político: de um lado, questionar o movimento feminista a respeito da hegemonia das mulheres brancas; de outro, tensionar o movimento negro sobre a prevalência de lideranças masculinas. Sueli Carneiro, a este respeito, propõe o enegrecimento do feminismo.

Enegrecendo o feminismo é a expressão que vimos utilizando para designar a trajetória das mulheres negras no interior do movimento feminista brasileiro. Buscamos assinalar, com ela, a identidade branca e ocidental da formulação clássica feminista, de um lado; e, de outro, revelar a insuficiência teórica e prática política para integrar as diferentes expressões do feminino construídos em sociedades multirraciais e pluriculturais (CARNEIRO, 2003, p. 118).

Para as mulheres negras, o feminismo hegemônico ainda estava assentado numa perspectiva eurocêntrica e colonialista e, portanto, não conseguia compreender os aspectos da formação social e histórica dos países latino-americanos, que foram explorados e colonizados, e onde o racismo permanece como base estrutural destas sociedades. A contribuição de Lélia Gonzalez permitirá observar que mesmo abolida a escravatura, permaneceu uma organização racial da sociedade que determina os lugares socialmente ocupados por negros, sejam homens ou mulheres. Em geral, tratam-se das ocupações mais precarizadas e, 
portanto, de menor prestígio, de mais baixos salários. Em seu clássico artigo Racismo e sexismo na cultura brasileira, enfatiza que o racismo constitui a "neurose da cultura brasileira" e "sua articulação com o sexismo produz efeitos violentos sobre a mulher negra em particular" (GONZÁLEZ, 1980, p. 224).

Esta violência remonta ao período escravocrata, quando a parte considerada mais produtiva da propriedade escrava era o ventre gerador. Os senhores de escravos, viam as mulheres negras como força de trabalho a ser empregada na produção, mas também reconhecia em seus corpos uma potência produtiva capaz de ampliar seu patrimônio. Este olhar senhorial retirava das mulheres negras o estatuto de humanidade, ao mesmo tempo em que imputava a elas a responsabilidade sobre sua própria condição de subalternidade.

Diz-se, geralmente, que a negra corrompeu a vida sexual da sociedade brasileira, iniciando precocemente no amor físico os filhos-família. Mas essa corrupção não foi pela negra que se realizou, mas pela escrava. Onde não se realizou através da africana, realizou-se através da escrava índia (FREYRE, 1994, p. 316).

Às mulheres escravizadas era transferida a responsabilidade pela identidade caricatural da qual ela era vítima, deixando de explicitar os abusos e violações dos senhores de escravos. Esta mesma situação foi identificada por Angela Davis (2016) em sua análise sobre o legado da escravidão nos Estados Unidos. Segundo a autora, como mulheres, as escravas eram submetidas a todas as formas de coerção sexual. Eram açoitadas, mutiladas e estupradas. O estupro, segundo a autora, "era uma expressão ostensiva do domínio econômico do proprietário e do controle do feitor sobre as mulheres negras na condição de trabalhadoras" (DAVIS, 2016, p. 20).

Às mulheres eram infligidos verdadeiros abusos com vistas a facilitar a cruel exploração econômica de seu trabalho. Como elas não eram consideradas mulheres pelos senhores de escravo, estes desencorajavam qualquer supremacia masculina dos homens negros. 
Com efeito, escreve a autora, "uma vez que as mulheres negras, enquanto trabalhadoras, não podiam ser tratadas como "sexo frágil" ou „donas de casa", os homens negros não podiam aspirar à função de „chefes de família“e, muito menos à de „provedores da família ${ }^{\text {ee” }}$ (DAVIS, 2016, p. 20). Além de força de trabalho, as mulheres também eram designadas para a função de "reprodutoras":

os proprietários buscavam garantir que suas "reprodutoras" dessem à luz tantas vezes quantas fosse biologicamente possível. Mas não iam tão longe a ponto de isentar do trabalho na lavoura as mulheres grávidas ou as mães com crianças de colo. Enquanto muitas mães eram forçadas a deixar os bebês deitados no chão perto da área em que trabalhavam, outras se recusavam a deixa-los sozinhos e tentavam trabalhar normalmente com eles presos às costas (DAVIS, 2016, p. 21).

Estes primeiros apontamentos, estão na base das críticas ao feminismo hegemônico. As mulheres negras advêm de uma experiência histórica diferenciada e o discurso clássico sobre a opressão da mulher não dá conta da diferença qualitativa da opressão sofrida pelas mulheres negras e o efeito que ela teve e tem ainda. Sueli Carneiro enfatiza que as negras - aliás, parte de um contingente majoritário de mulheres - não reconheceram em si mesmas o mito da fragilidade porque, escreve a autora, "nunca fomos tratadas como frágeis" (Carneiro, 2003). Para a autora, se ontem, as mulheres negras estavam a serviço de frágeis sinhazinhas e de senhores de engenho tarados, hoje elas são as empregadas domésticas de mulheres liberadas e dondocas (CARNEIRO, 2003).

As mulheres negras continuam a ocupar os lugares subalternos, estão entre as maiores taxas de desemprego e permanecem por mais tempo desocupadas. Quando estão empregadas, lhes são reservadas as ocupações de menor qualidade, status e remuneração. De acordo com o Dieese, elas estão engajadas "em ocupações caracterizadas pela precariedade e enfrentando dificuldades para ascensão em suas carreiras profissionais". Além disso, há uma preponderância de negras 
na atividade doméstica, categoria historicamente reconhecida como o segmento mais inferiorizado do mercado de trabalho, onde

$$
\begin{aligned}
& \text { agregam-se pessoas mal remuneradas e } \\
& \text { principalmente trabalhadores informais, sem } \\
& \text { carteira de trabalho assinada, nem contribuição } \\
& \text { previdenciária. Segundo os dados do censo de 2010, } \\
& \text { os empregados domésticos agregam quase cinco } \\
& \text { milhões de } \\
& \text { trabalhadores. Historicamente esta ocupação } \\
& \text { sempre foi numerosa no Brasil e, apesar de sua } \\
& \text { contínua redução, ainda representa } 6 \% \text { das pessoas } \\
& \text { ocupadas no país. Os empregados domésticos } \\
& \text { constituem uma categoria marcada pela baixa } \\
& \text { escolaridade (60\% tem até o fundamental } \\
& \text { incompleto), com predominância da população } \\
& \text { negra (61,6\%) e majoritariamente feminina (94,4\%) } \\
& \text { (MACHADO; LIMA, 2016, s/p). }
\end{aligned}
$$

Estes dados evidenciam o que embora o feminismo hegemônico tenha lutado e conseguido ganhos importantes no que diz respeito ao trabalho feminino, há ainda uma lacuna abissal com relação às mulheres negras. Os ganhos obtidos pela luta feminista no mercado de trabalho, como escreve Sueli Carneiro, não

conseguiram dirimir as desigualdades raciais que obstaculizam maiores avanços para as mulheres negras nessa esfera. Sendo assim, as propostas universalistas da luta das mulheres não só mostram a sua fragilidade, como a impossibilidade de as reivindicações que daí advêm, tornarem-se viáveis para enfrentar as especificidades do racismo brasileiro (2003, p. 120).

Ao examinar esta realidade, Lélia Gonzalez constata que há uma divisão sexual do trabalho, mas também existe uma divisão racial do trabalho. Segundo a autora, não é possível analisar o caso brasileiro sem somar à divisão sexual a divisão racial, constantemente camuflada sob o manto do mito da democracia racial. Na divisão racial do trabalho, a "mulher negra, naturalmente, é cozinheira, faxineira, servente, cobradora de ônibus ou prostituta". A autora indaga: "Por 
que será que ela só desempenha atividades que não implicam em „lidar com o público“e? Ou seja, em atividades onde não podem ser vistas? Por que os anúncios de emprego falam tanto em „boa aparência“"?" (GONZALEZ, 1980, p. 233). E o que é ter uma boa aparência?

O quesito "boa aparência", segundo Carneiro, é "um eufemismo sistematicamente denunciado pelas mulheres negras como uma forma sutil de barrar as aspirações dos negros, em geral, e das mulheres negras, em particular, revelava em números, no mercado de trabalho, todo o seu potencial discricionário" (CARNEIRO, 2003, p. 121). Essa realidade vivenciada pela população negra em geral, e em particular pela mulher negra, corrobora com as análises realizadas por Lélia González (1980) acerca da existência da divisão racial do trabalho. E a autora vai além. Para González, a divisão racial extrapola as relações de trabalho e abrange todas as áreas da vida social. Isto fica evidente quando se examina os espaços sistematicamente reservados à população negra: pouco acesso à educação, condições precárias de moradia e vagas nos empregos mais precários. Tudo se organiza como se cada grupo ocupasse um "lugar natural" que lhe é reservado:

O lugar natural do grupo branco dominante são moradias saudáveis, situadas nos mais belos recantos da cidade ou do campo e devidamente protegidas por diferentes formas de policiamento que vão desde os feitores, capitães de mato, capangas, etc, até à polícia formalmente constituída. Desde a casa grande e do sobrado até aos belos edifícios e residências atuais, o critério tem sido o mesmo. Já o lugar natural do negro é o oposto, evidentemente: da senzala às favelas, cortiços, invasões, alagados e conjuntos "habitacionais" (...) dos dias de hoje, o critério tem sido simetricamente o mesmo: a divisão racial do espaço (...). No caso do grupo dominado o que se constata são famílias inteiras amontoadas em cubículos, cujas condições de higiene e saúde são as mais precárias. Além disso, aqui também se tem a presença policial; só que não é para proteger, mas para reprimir, 
violentar e amedrontar (GONZÁLEZ, 1980, p. 232233).

Estas observações tornam evidentes a existência de uma divisão racial do trabalho na sociedade, que reserva lugares socialmente distintos (sobretudo mais precários) aos trabalhadores e às trabalhadoras negras/os.

\section{Moldando o feminismo negro}

As observações de Lélia Gonzalez a conduz cada vez mais a analisar a condição da mulher negra na sociedade brasileira. Mesmo atuante no movimento feminista, percebia a necessidade de uma autonomia das mulheres negras, na medida em que o discurso daquele movimento sobre a opressão de gênero, estruturada pela "ideologia patriarcal não dá conta da diferença qualitativa que este tipo de opressão teve e tem ainda na construção da identidade feminina da mulher negra" (CARNEIRO; SANTOS, 1985, p. 42). As fronteiras com o movimento feminista apareceram, por exemplo, quando mulheres negras discutiam a necessidade da luta por creches comunitárias e eram contestadas por feministas brancas. A este respeito, Rosália Lemos escreve o seguinte: "éramos as babás e as empregadas domésticas de suas casas e as nossas crianças ficavam "soltas" nas favelas quando trabalhávamos" (Lemos, 2016, p. 19). A luta por creches comunitárias se torna paulatinamente uma bandeira feminista, tamanha a importância para as mulheres moradoras das áreas pobres, majoritariamente negras.

O caráter universalizante do discurso feminista impedia a percepção das desigualdades raciais. Todavia, a participação nos movimentos negros trazia outra dimensão do problema: as práticas sexistas e machistas dos homens que lideravam tais movimentos, evidenciando que a luta contra o racismo era ineficaz se não fosse atrelada à luta contra o machismo. Definitivamente, só confeccionar cartazes ou ficar nas cozinhas preparando comida não era o que 
queriam; tampouco almejavam serem as recepcionistas do movimento ou desempenhar apenas atividades tidas "naturalmente" como femininas. Porém, mesmo percebendo as vantagens que o patriarcado possibilita aos homens negros em comparação com as mulheres negras, elas estavam conscientes do peso da discriminação racial sobre eles. Esta constatação de que, em geral, os homens negros estão em situação inferior às mulheres não negras, levou Sueli Carneiro e Thereza Santos a afirmarem que não cabe "a suposição de que uma perspectiva feminista para o movimento de mulheres negras passe pela oposição ou distanciamento do homem negro" (1985, p. 37).

Era fundamental atrelar a luta contra o racismo à luta antissexista. Era necessário, "enegrecer" a agenda feminista e introduzir a pauta feminista no movimento negro (CARNEIRO, 2003). Era urgente lidar com a simultaneidade das opressões estruturantes da sociedade capitalista. Lélia Gonzalez, no interior do grupo de mulheres Nzinga, do Rio de Janeiro, refletia com as demais sobre a maneira como o feminismo das mulheres brancas não conseguia inserir as reivindicações das mulheres negras em suas lutas; e desde os anos setenta sentia a necessidade de um feminismo que tivesse a cara da mulher cor de azeviche.

Gonzalez (2018) no artigo "Mulher negra na sociedade brasileira", publicado pela primeira vez em 1981, ao se referir ao movimento feminista, viu na negação do racismo o objetivo de camuflar a dominação e a exploração exercidas pelas mulheres brancas sobre as mulheres negras. Para ela, as feministas brancas, mesmo com orientações progressistas e de esquerda, não perceberam a importância da inserção da pauta racial. A unanimidade que havia em torno da luta contra a exploração da mulher e do operariado deixava de existir quando o assunto era a discussão sobre o racismo e o significado da raça na vida de mulheres negras. Em suas palavras:

Nossa fala foi acusada de emocional por umas e até mesmo de revanchista por outras, todavia, as representantes de regiões mais pobres nos 
entenderam perfeitamente (eram mestiças em sua maioria). Toda a celeuma causadora por nosso posicionamento significou, para nós, a caracterização de um duplo sintoma: de um lado, o atraso político (principalmente dos grupos que consideravam mais progressistas) e do outro, a grande necessidade de denegar o racismo para ocultar uma outra questão: a exploração da mulher negra pela mulher branca (GONZALEZ, 2018, p. 48).

A agenda do feminismo desconsiderava a luta antirracista, mais que isso, as relações raciais eram o abismo que separava as mulheres brancas das mulheres negras. Esta perspectiva coloca Lélia Gonzalez (2018) na origem do pensamento interseccional, em especial em sua constatação de que as mulheres negras permaneciam o setor mais explorado e oprimido da sociedade brasileira, uma vez que sofrem uma tríplice discriminação (social, racial e sexual). Vem de Lélia Gonzalez o aporte teórico e político de enfrentamento à herança escravista, à opressão patriarcal e à exploração capitalista de classe.

\section{Referências}

BARRETO, Raquel. Enegrecendo o feminismo ou feminizando a raça: narrativas de libertação em Ângela Davis e Lélia Gonzalez. Dissertação (Mestrado em História). Pontifícia Universidade Católica do Rio de Janeiro, Rio de Janeiro, 2005.

CARNEIRO, Sueli. Mulheres em movimento. Estudos Avançados, n. 17 (49), São Paulo, 2003.

CARNEIRO, Sueli; SANTOS, Thereza. Mulher Negra. São Paulo: Nobel, 1985.

DAVIS, Angela. Mulheres, Raça e Classe. São Paulo: Boitempo, 2016.

FREYRE, Gilberto. Casa-grande E senzala. São Paulo: Global, 1994.

GONÇALVES, Renata. Lélia Gonzalez: primavera para as rosas negras' (resenha). Plural (USP), v. 26, n. 1, 2019. 
GONZALEZ, Lélia. Primavera para as rosas negras: Lélia Gonzalez em primeira pessoa. São Paulo: Diáspora Africana, 2018.

GONZALEZ, Lélia. O movimento negro na última década. In: GONZALEZ, Lélia; HASENBALG, Carlos. Lugar de negro. Rio de Janeiro: Marco Zero, 1982.

GONZALEZ, Lélia. Racismo e sexismo na cultura brasileira. In: IV Encontro Anual da Associação Nacional de Pós-Graduação e Pesquisa em Ciências Sociais. Rio de Janeiro, 1980.

LEMOS, Rosalia de Oliveira. Os feminismos negros: a reação aos sistemas de opressões. Revista Espaço Acadêmico, Maringá, n. 185, p. 12-25, 2016.

LEMOS, Rosalia de Oliveira. A face negra do feminismo: problemas e perspectivas. In: WERNECK, Jurema; MENDONÇA, Maísa; WHITE, Evelyn (orgs.). O livro da saúde das mulheres negras: nossos passos vêm de longe. Rio de Janeiro: Pallas/Criola, 2006. p. 64-67.

MACHADO, Marta Rodriguez de Assis; LIMA, Márcia Lima. Trabalho doméstico no Brasil: afetos desiguais e as interfaces de classe, raça e gênero. Portal Geledés. 2016.2 Disponível em: https:/ / www.geledes.org.br/trabalho-domestico-no-brasil-afetosdesiguais-e-as-interfaces-de-classe-raca-e-genero/. Acesso em: 09 jan. 2018.

SOUZA, Neusa Santos. Tornar-se negro. São Paulo: Brasiliense, 1983. 